\title{
Past and future scenarios of the effect of carbon dioxide on plant growth and transpiration for three vegetation types of southwestern France
}

\author{
J.-C. Calvet, A.-L. Gibelin, J.-L. Roujean, E. Martin, P. Le Moigne, H. Douville, and J. Noilhan \\ CNRM/GAME (Météo-France, CNRS), Toulouse, France
}

Received: 19 January 2007 - Published in Atmos. Chem. Phys. Discuss.: 5 April 2007

Revised: 28 September 2007 - Accepted: 21 December 2007 - Published: 29 January 2008

\begin{abstract}
The sensitivity of an operational $\mathrm{CO}_{2}$-responsive land surface model (the ISBA-A-gs model of Météo-France) to the atmospheric $\mathrm{CO}_{2}$ concentration, $\left(\mathrm{CO}_{2}\right)$, is investigated for 3 vegetation types (winter wheat, irrigated maize, coniferous forest). Past (1960) and future (2050) scenarios of $\left(\mathrm{CO}_{2}\right)$ corresponding to $320 \mathrm{ppm}$ and $550 \mathrm{ppm}$, respectively, are explored. The sensitivity study is performed for 4 annual cycles presenting contrasting conditions of precipitation regime and air temperature, based on continuous measurements performed on the SMOSREX site near Toulouse, in southwestern France. A significant $\mathrm{CO}_{2}$-driven reduction of canopy conductance is simulated for the irrigated maize and the coniferous forest. The reduction is particularly large for maize, from 2000 to $2050(-18 \%)$, and triggers a drop in optimum irrigation $\left(-30 \mathrm{~mm} \mathrm{y}^{-1}\right)$. In the case of wheat, the response is more complex, with an equal occurrence of enhanced or reduced canopy conductance.
\end{abstract}

\section{Introduction}

Carbon dioxide $\left(\mathrm{CO}_{2}\right)$ has a direct effect on plant transpiration. On one hand, the carbon fertilization yields an increase of the vegetation biomass and, to a lesser extent, of the leaf area index (LAI). On the other hand, the antitranspirant action of $\mathrm{CO}_{2}$ infers a reduction of the leaf stomatal conductance to water vapour regulating the latent heat flux. The competition between the two phenomena may either result in an increase or a decrease of canopy conductance $\left(g_{c}\right)$, this depending on plant characteristics, climatic conditions, and nutrient availability (Field et al., 1995; Douville et al., 2000). A recent study (Gedney et al., 2006) has led to the conclusion that direct effect of $\mathrm{CO}_{2}$ on plant stands may have been a contributor to an enhancement of river flows during the 20th

Correspondence to: J.-C. Calvet

(calvet@meteo.fr) century. However, they did not consider the impact of increasing biomass and LAI due to increased atmospheric $\mathrm{CO}_{2}$ concentration $\left(\mathrm{CO}_{2}\right)$.

In numerical weather prediction (NWP) models, hourly fields of the surface temperature, the water and heat fluxes, are produced through dedicated module interfaces. MétéoFrance is developing SURFEX (SURFace EXternalisée) to be used in operational NWP models, and offline for applications in hydrology and vegetation monitoring (Martin et al., 2007). SURFEX serves the merging of a number of land and ocean surface models. Over land, SURFEX includes ISBA-A-gs, a $\mathrm{CO}_{2}$ responsive land surface model able to simulate the diurnal cycle of carbon and water vapor fluxes (Calvet et al., 1998; Calvet et al., 2004; Gibelin et al., 2006). This latter model accounts for different feedbacks in response to changes in $\left(\mathrm{CO}_{2}\right)$, photosynthesis enhancement and transpiration reduction. Daily values of LAI and biomass can be produced by ISBA-A-gs. A previous study showed that ISBA-A-gs is able to represent $\mathrm{CO}_{2}$-enrichment effects (Calvet and Soussana, 2001) on plant transpiration and plant growth.

In this study, the impact of the rapid increase in $\left(\mathrm{CO}_{2}\right)$ on land surface processes, that is photosynthesis and transpiration, is investigated by simulating LAI with ISBA-Ags offline. The objective is to assess to what extent the use of a $\mathrm{CO}_{2}$-responsive land surface model is needed in current and future operational NWP simulations. The model is run offline over the experimental Surface Monitoring Of the Soil Reservoir Experiment (SMOSREX, De Rosnay et al., 2006) site and we take benefit of having a period of 4 contrasted years. The fallow site of SMOSREX is chosen because long-term continuous observations of atmospheric variables are available, together with vegetation biomass and soil moisture content measurements. These data were used in another study to validate the control simulations of ISBAA-gs and test different methods of data assimilation in the model (Muñoz Sabater et al., 2007).

Published by Copernicus Publications on behalf of the European Geosciences Union. 
Table 1. Four contrasting annual cycles (Y1, Y2,Y3, Y4), derived from the SMOSREX data set: average maximum air temperature (degree C), Tx, for quarters 2 and 3 (AMJ and JAS, respectively), cumulated annual and quarterly precipitation, RR (mm).

\begin{tabular}{cccccccl}
\hline Annual cycle & Year & AMJ Tx & JAS Tx & Annual RR & AMJ RR & JAS RR & Characteristics \\
\hline Y1 & 2001 & 20.7 & 26.1 & 621 & 179 & 173 & Normal year \\
Y2 & 2002 & 20.5 & 25.0 & 677 & 228 & 137 & Wet year; cool summer \\
Y3 & 2003 & 23.4 & 30.0 & 574 & 80 & 144 & Dry Spring; hot \\
Y4 & 2004 & 21.0 & 27.3 & 677 & 196 & 100 & Dry Summer; warm \\
\hline
\end{tabular}

Emphasis is given on the net $\left(\mathrm{CO}_{2}\right)$ effect on canopy conductance $g_{c}$ for past (from 1960 to 2000) and future scenarios (from 2000 to 2050). Three vegetation types found in southwestern France are considered: winter wheat, irrigated maize, and coniferous forest. A method to account for nitrogen dilution and the implementation of a sensitivity study are described in Sect. 2. The results are presented in Sect. 3 and the model's response to $\left(\mathrm{CO}_{2}\right)$ is analysed and discussed in Sect. 4.

\section{Material and methods}

\subsection{Forcing atmospheric data}

Atmospheric and radiation variables are continuously measured at the weather station of the SMOSREX research site located near Toulouse $\left(43^{\circ} 230 \mathrm{~N}, 1^{\circ} 170 \mathrm{E}\right.$, at $188 \mathrm{~m}$ altitude), in southwestern France. SMOSREX is a long-term experiment devoted to land surface monitoring studies, which started in 2001 (De Rosnay et al., 2006). In this study, we take advantage of having four contrasting annual cycles during the period 2001-2004 (Table 1), where continuous halfhourly time series of air temperature and humidity, wind speed, precipitation, shortwave and longwave down-welling radiation observations were acquired.

\subsection{Parameters of ISBA-A-gs}

In this study, we use the same model and the same model parameters obtained at a global scale by Gibelin et al. (2006) (Gi06). However, we must prescribe specific values of the leaf nitrogen concentration, $N_{L}$ because this parameter depends on the environmental conditions, and particularly in nutrient availability (Table 2). Another difference with the Gi06 simulation is that, for maize, a sowing date is prescribed (15 May) and the irrigation is simulated: (1) From 1 January to the sowing date, LAI is forced below a minimum value of $0.3 \mathrm{~m}^{2} \mathrm{~m}^{-2}$; (2) An irrigation amount of $30 \mathrm{~mm}$ is added to the precipitation forcing each time the simulated extractable soil moisture content (dimensionless) reaches a predefined threshold. This threshold decreases from 0.70 for the first irrigation, to 0.55 for the second, 0.40 for the third, and 0.25 for the following ones.
Differences in rooting depth are accounted for by assuming that the maximum extractable soil moisture is higher for conifer: $260 \mathrm{~kg} \mathrm{~m}^{-2}$, against $124 \mathrm{~kg} \mathrm{~m}^{-2}$ for wheat or maize.

The ecosystem respiration $R_{e}$ is represented by a $Q_{10}$ temperature-response function (Rivalland et al., 2005):

$$
R_{e}=R_{e 25} \cdot Q_{10}^{\left(T_{2}-25\right) / 10}
$$

where $R_{e 25}$ is the baseline ecosystem respiration at a nearsurface soil temperature $\left(T_{2}\right)$ of 25 degree C. $T_{2}$ is a variable simulated by the model, and in this study a $Q_{10}$ value of 2 is used. Similarly to Gi06, simulations are performed offline, that is no coupling with the atmospheric boundary layer is performed, and a constant value of $\left(\mathrm{CO}_{2}\right)$ is prescribed.

The ISBA-A-gs model simulates the above-ground green biomass and can be used for various types of vegetation like annual crops or forests. In the case of forests, the model is able to represent the leaf biomass but the wood part (presenting a decadal life-span) is not simulated. Thanks to a high value of the maximum leaf span time ( $\tau_{M}$ of 365 days), the simulated LAI of a coniferous forest is higher than $2 \mathrm{~m}^{2} \mathrm{~m}^{-2}$ at wintertime. Namely, an evergreen canopy is simulated, not an annual one. Since the wood biomass is not simulated, the impact of $\left(\mathrm{CO}_{2}\right)$ on the decadal coupling between biomass and other variables of the conifer forest ecosystem is not considered in this study. However, the first order response of hourly to seasonal processes should be represented relatively well. Recent work has shown that ISBA-A-gs is able to represent the hourly, seasonal and interannual variability of the water and carbon fluxes of conifer forests, both at the local scale (Rivalland et al., 2005) and at the global scale, in various climatic conditions (Gi06). Moreover, the model was favourably compared to other approaches in the framework of a model intercomparison initiative (Viovy, 2003), over the Scots pine forest of Loobos (Dolman et al., 2002).

\subsection{Scenarios for a sensitivity test}

Contrasting $\left(\mathrm{CO}_{2}\right)$ situations are considered for past and future decades: (1) $320 \mathrm{ppm}$ is representative of the early $1960 \mathrm{~s}$ (Keeling et al., 1996), (2) $550 \mathrm{ppm}$ is projected for the year 2050 (Long et al., 2006). The reference situation is $371 \mathrm{ppm}$, corresponding to 2000 (Fung et al., 2005). Changes in the precipitation regime and the mean air temperature are not di- 
Table 2. Standard values of ISBA-A-gs parameters (Gibelin et al., 2006) for 3 vegetation types (Winter wheat, irrigated maize, coniferous forest) and specific values of leaf nitrogen concentration $N_{L}$ and ecosystem respiration at 25 degree C $R_{e 25}$, for southwestern France (SWF). $N_{L}$ in $\%$ of dry mass. $g_{m} *$ is the mesophyll conductance in well-watered conditions, in $\mathrm{mm} \mathrm{s}^{-1}, \tau_{M}$ is the maximum leaf span time, in days, $\mathrm{LAI}_{\min }$ is the minimum leaf area index, in $\mathrm{m}^{2} \mathrm{~m}^{-2}, g_{c}$ is the cuticular conductance, in $\mathrm{mm} \mathrm{s}^{-1}, \theta_{C}$ is the critical extractable soil moisture content, dimensionless, $e$ is the SLA (specific leaf area) sensitivity to $N_{L}$, in $^{2} \mathrm{~kg}^{-1} \%{ }^{-1}, f$ is SLA at $N_{L}=0 \%$, in $\mathrm{m}^{2} \mathrm{~kg}^{-1}, R_{e 25}$ is in $\mathrm{mgCO}_{2} \mathrm{~m}^{2} \mathrm{~s}^{-1}$.

\begin{tabular}{cccccccccccccc}
\hline Vegetation Type & Photosynthesis type & $\mathrm{SWF} N_{L}$ & $N_{L}$ & $g_{m}^{*}$ & $\tau_{M}$ & $\mathrm{LAI}_{\min }$ & $g_{c}$ & $\theta_{C}$ & $\mathrm{e}$ & $\mathrm{f}$ & $R_{e 25}$ & Response to drought \\
\hline Wheat & $\mathrm{C} 3$ & 1.1 & 1.3 & 1 & 150 & 0.3 & 0.25 & 0.3 & 3.79 & 9.84 & 0.27 & avoiding \\
Maize & $\mathrm{C} 4$ & 2.2 & 1.9 & 9 & 150 & 0.3 & 0.15 & 0.3 & 7.68 & -4.33 & 0.53 & tolerant \\
Conifer & $\mathrm{C} 3$ & 2.3 & 2.8 & 2 & 365 & 1 & 0 & 0.3 & 4.85 & -0.24 & 0.56 & avoiding \\
\hline
\end{tabular}

rectly represented. However, four contrasting years are considered: 2001 is rather representative of the present climatology; 2002 was a wet and cool year; 2003 and 2004 were dry and warm years; 2003 was especially hot, with a monthly average maximum air temperature 3.6 to 5.7 degree $\mathrm{C}$ higher than the same period in 2001, from June to August. These latter two are expected to represent future climates scenarios (Table 1).

The model used in this study is not a crop (forestry) model and does not account for changes in agricultural (forestry) practices with time (such as the use of fertilisers, herbicides, pesticides, or the genetic improvement of the cultivars). Therefore, the $\left(\mathrm{CO}_{2}\right)$ effect is analysed alone. Namely, the same plant, in the same climate and nutrient availability conditions is considered for past, present and future situations. Local simulations are performed and the spatial variability of important factors like soil texture and water holding capacity, precipitation, is not investigated.

\subsection{Representation of nitrogen dilution}

The $\mathrm{CO}_{2}$ fertilization effect tends to increase the vegetation biomass but this effect is limited by nitrogen dilution. In this study, nitrogen dilution is accounted for by parameterizing the change in leaf nitrogen mass-based concentration $N_{L}$ in response to $\left(\mathrm{CO}_{2}\right)$ rise. The sensitivity of leaf nitrogen concentration versus $\left(\mathrm{CO}_{2}\right)$ is accounted for by using the meta-analysis of the literature carried out by Yin 2002 (Yi02). The meta-analysis of Yi02 indicates that, on average, a $\mathrm{CO}_{2}$-doubling causes a $18 \%$ decrease in $N_{L}$, but that the $N_{L}$ response to $\mathrm{CO}_{2}$ is influenced by a number of factors. A change in $\left(\mathrm{CO}_{2}\right)$, from $\left(\mathrm{CO}_{2}\right)=\mathrm{C}_{1}$ to $\left(\mathrm{CO}_{2}\right)=\mathrm{C}_{2}$, produces a change in $N_{L}$ from $N_{L 1}$ to $N_{L 2}$ following:

$$
\ln \left(\frac{N_{L 2}}{N_{L 1}}\right)=-a \exp \left[b-\frac{N_{L 1}}{N_{L \max }}\right] \ln \left(\frac{\mathrm{C}_{2}}{\mathrm{C}_{1}}\right)
$$

with $a=0.048$ and $N_{L \max }=6.3 \%$. In the Yi02 study, $\mathrm{C}_{2} / \mathrm{C}_{1}$ ranges from 0.53 to 3.2 . The $b$ parameter may vary significantly from one vegetation type to another. For example, in median radiation and air temperature (Ta) conditions, $b=1.48$ for a fertilised crop, $b=2.56$ for a deciduous forest, $b=1.81$ for a coniferous forest or natural grasslands.

The values of $b$ are given by:

$b=0.75 \mathrm{DF}-0.33 \mathrm{FERT}+1.1 \mathrm{PPFD}+\frac{T_{a}}{23}$

with $\mathrm{DF}=1$ for deciduous forests (0 for other biomes), and FERT $=1$ for fertilized ecosystems like crops ( 0 for other biomes). PPFD is the average photosynthetically active solar radiation reaching the leaf within the vegetation canopy (median value of $0.74 \mathrm{mmol} \mathrm{m}^{-2} \mathrm{~s}^{-1}$, equivalent to a total solar radiation of $335 \mathrm{Wm}^{-2}$ ). In this study, no solar radiation or temperature effect is associated with a change in $\left(\mathrm{CO}_{2}\right)$ and the median PPFD and Ta values of Yi02 are used in Eq. (3).

\subsection{Analysis of the $\left(\mathrm{CO}_{2}\right)$ impact}

In this study, a sensitivity study to $\left(\mathrm{CO}_{2}\right)$ is performed. The direct, antitranspirant effect of $\mathrm{CO}_{2}$ is modelled at the hourly scale. The indirect, cumulative effect of $\mathrm{CO}_{2}$ on LAI and soil moisture at the seasonal and interannual scales, is accounted for. The changes are due to $\mathrm{CO}_{2}$ variations only. The soil and vegetation parameters of the model (except for $N_{L}$, which depends on $\mathrm{CO}_{2}$ ) remain unchanged. The scenario impacts are analysed in respect to five hourly variables (canopy conductance $g_{c}$, mean leaf temperature Ts, water vapour and heat fluxes, net ecosystem exchange of carbon NEE) and one daily variable (LAI).

Only the situations favourable to significant landatmosphere exchanges controlled by the vegetation are considered. The time periods are chosen by applying the following criteria to the 2000 reference simulation: (1) a significant amount of green biomass: LAI $>1 \mathrm{~m}^{2} \mathrm{~m}^{-2}$, (2) medium to high levels of available energy for turbulent fluxes of sensible and latent heat flux ( $\mathrm{H}$ and LE, respectively): $\mathrm{H}+\mathrm{LE}>200 \mathrm{Wm}^{-2}$, (3) moderate to high leaf temperature: Ts $>15$ degree $C$. These thresholds act at filtering out nocturnal and wintertime situations mainly. For crops, the threshold fixed on LAI values serves to segregate the growing period (March-June for wheat, June-September for maize) as well as a possible regrowth (from August to October in the case 
Table 3. Flux and biomass annual production for the 2000 reference simulation, for 3 vegetation types: winter wheat, irrigated maize, and coniferous forest. The results are presented for four contrasting annual cycles (Y1 to Y4, Table 1). GPP is gross primary production (i.e. raw carbon uptake by photosynthesis).

\begin{tabular}{llllll}
\hline Variable & Type & Y1 & Y2 & Y3 & Y4 \\
\hline Evapotranspiration $\left(\mathrm{mm} \mathrm{y}^{-1}\right)$ & Wheat & 570 & 561 & 444 & 469 \\
GPP $\left(\mathrm{gC} \mathrm{m}^{-2}\right)$ & Wheat & 1419 & 1480 & 1150 & 1181 \\
Maximum LAI $\left(\mathrm{m}^{2} \mathrm{~m}^{-2}\right)$ & Wheat & 5.7 & 5.7 & 4.7 & 5.4 \\
Maximum leaf biomass $\left(\mathrm{kg} \mathrm{m}^{-2}\right)$ & Wheat & 0.38 & 0.37 & 0.32 & 0.36 \\
Maximum aboveground biomass $\left(\mathrm{kg} \mathrm{m}^{-2}\right)$ & Wheat & 1.36 & 1.32 & 1.04 & 1.26 \\
Optimum irrigation $\left(\mathrm{mm} \mathrm{y}^{-1}\right)$ & Maize & 120 & 60 & 270 & 240 \\
Evapotranspiration $\left(\mathrm{mm} \mathrm{y}^{-1}\right)$ & Maize & 526 & 483 & 616 & 563 \\
GPP $\left(\mathrm{gC} \mathrm{m}^{-2}\right)$ & Maize & 2567 & 2394 & 2658 & 2396 \\
Maximum LAI $\left(\mathrm{m}^{2} \mathrm{~m}^{-2}\right)$ & Maize & 6.25 & 5.97 & 6.14 & 6.07 \\
Maximum leaf biomass $\left(\mathrm{kg} \mathrm{m}^{-2}\right)$ & Maize & 0.47 & 0.45 & 0.46 & 0.45 \\
Maximum aboveground biomass $\left(\mathrm{kg} \mathrm{m}^{-2}\right)$ & Maize & 1.92 & 1.78 & 1.84 & 1.80 \\
Evapotranspiration $\left(\mathrm{mm} \mathrm{y}^{-1}\right)$ & Conifer & 544 & 520 & 528 & 519 \\
GPP $\left(\mathrm{gC} \mathrm{m}^{-2}\right)$ & Conifer & 2614 & 2621 & 2316 & 2334 \\
Maximum LAI $\left(\mathrm{m}^{2} \mathrm{~m}^{-2}\right)$ & Conifer & 5.7 & 5.8 & 5.3 & 5.5 \\
Maximum leaf biomass $\left(\mathrm{kg} \mathrm{m}^{-2}\right)$ & Conifer & 0.49 & 0.50 & 0.46 & 0.48 \\
Maximum aboveground biomass $\left(\mathrm{kg} \mathrm{m}^{-2}\right)$ & Conifer & - & - & - & - \\
\hline
\end{tabular}

of wheat). This corresponds from $10 \%$ to $15 \%$ of the 4-year hourly simulations, that is about $4200 \mathrm{~h}$ for wheat, $3500 \mathrm{~h}$ for maize, and $5300 \mathrm{~h}$ for conifer.

\section{Results}

\subsection{The reference simulation (year 2000)}

Table 3 presents a yearly summary of the current climate simulations (for year 2000), for wheat, maize, and conifer. The dry/warm years Y3 and Y4 contrast sharply with the Y1 and $\mathrm{Y} 2$ annual cycles. For maize, much higher irrigation amounts are simulated in Y3 and Y4 (up to $270 \mathrm{~mm} \mathrm{y}^{-1}$ ) and higher evapotranspiration (more than $560 \mathrm{~mm} \mathrm{y}^{-1}$ ) and gross primary production (GPP). However, the rainfed wheat presents lower values of evapotranspiration and GPP in Y3 and Y4.

Figure 1 presents the simulated wheat, maize, and conifer LAI for Y1, Y2, Y3, and Y4. Existing field experiments and agricultural statistics can be used to assess a number of variables simulated by the model. The LAI simulations, for example, are consistent with field observations (Dolman et al., 2006) performed in 2005 in southwestern France over wheat and maize. In the case of a wheat crop (Lamasquère), maximum LAI was attained in May and the senescence occurred in June. The maximum LAI of an irrigated maize (Saint-Sardos) was attained in July and remained stable till the senescence, which occurred in October. Our simulations over 4 consecutive years are agreeing with these observations. It is more difficult to validate the absolute value of LAI, which is affected by a high spatial variability. Bondeau et al. (2007) give maximum LAI values for fertilized wheat and maize comprised between 3 and $7 \mathrm{~m}^{2} \mathrm{~m}^{-2}$, and our simulations fall into this interval.

Estimates of irrigation amounts for maize are given by Teyssier (2006) over Haute-Garonne, an administrative region of $6309 \mathrm{~km}^{2}$ covering the SMOSREX site. From Y1 to Y4, he gives: 198, 130, 294, $228 \mathrm{~mm} \mathrm{y}^{-1}$, respectively. These estimates are strongly correlated $\left(r^{2}=0.88\right)$ with the optimal irrigation produced by the model (Table 3). However, during the wet years $\mathrm{Y} 1$ and $\mathrm{Y} 2$, the modelled irrigation is markedly underestimated by the model (78 and $70 \mathrm{~mm} \mathrm{y}^{-1}$, respectively). The difference is smaller during the dry years Y3 and Y4 (24 and $-12 \mathrm{~mm} \mathrm{y}^{-1}$, respectively, less than the $30 \mathrm{~mm}$ irrigation step used in the model). The model simulates the optimal irrigation, which may differ from the actual irrigation resulting from the agricultural practices. In particular, the difference between the simulated optimal irrigation and the actual irrigation amounts during wet years may be caused by higher irrigation intensities when the water resource available for irrigation is not limited by drought. This effect is particularly noticeable for Y1 (Teyssier, 2006; Debaeke et al., 2006).

Crop yield estimates for Haute-Garonne are available (Agreste, 2007). The model simulates the above-ground biomass of crops (Table 3) and does not simulate the crop yield. However, the correlation between the maximum above-ground biomass and independent yield estimates may help verify the model capability to represent the interannual variability. First, the long-term trend in yield increase has to be removed from the observed time series (Debaeke et 

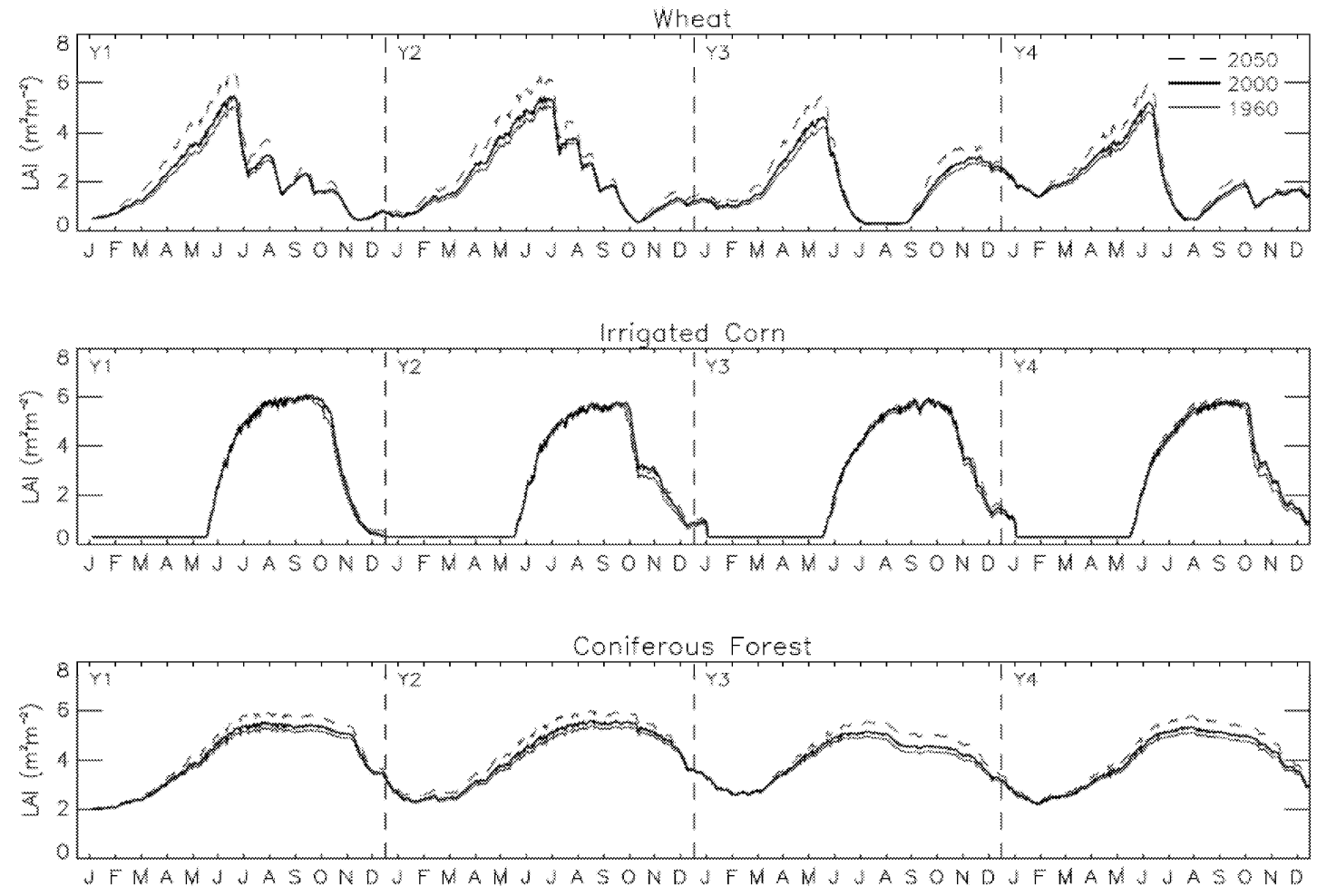

Fig. 1. Leaf area index (LAI), simulated by ISBA-A-gs for wheat, maize, and conifer in present (2000), past (1960), and future (2050) (CO 2 ) conditions (thick, fine, dashed curves, respectively).

al., 2006) and yield anomalies are obtained from 2001 to 2004: $-0.03,+0.03,-0.07,+0.01 \mathrm{~kg} \mathrm{~m}^{-2}$ for wheat, and $+0.05,-0.04,-0.17,-0.06 \mathrm{~kg} \mathrm{~m}^{-2}$ for maize, respectively. A positive correlation if found for wheat and maize, relatively good for wheat $\left(r^{2}=0.47\right)$, poor for maize $\left(r^{2}=0.18\right)$. In the case of maize, the biomass simulated by the model does not present the severe drop observed for yield in Y3. The maize yield figures available on Agreste do not separate irrigated from rainfed maize but Debaeke et al. (2006) show that irrigated maize suffered a loss of yield in Y3 (12\% instead of $30 \%$ for rainfed maize).

The ratio of crop yield to the maximum above-ground biomass is called the harvest index. According to Bondeau et al. (2007), typical harvest index values for wheat and maize in well watered conditions (e.g. Y1 or Y2 in this study) are about 0.4 and 0.5 , respectively. The average harvest index derived from yield estimates for Haute-Garonne and from the simulated maximum above-ground biomass for Y1 and Y2 is 0.41 for wheat and 0.45 for maize. The relatively low harvest index we obtain for maize may denote an overestimation of the simulated maximum above-ground biomass of about $10 \%$.

The simulated conifer LAI presents a marked annual cycle, with minimum values in January-February and maximum values in July-August, respectively. No (or little) inter- annual variability is simulated. This is consistent with in situ LAI observations at the Le Bray site in southwestern France (Berbigier et al., 2001; Rivalland et al., 2005).

\subsection{Past and future scenarios of $\left(\mathrm{CO}_{2}\right)$ impact}

In this section, statistical indices are given about changes in biophysical variables caused by past and future changes in $\left(\mathrm{CO}_{2}\right)$, for wheat, maize, and conifer. The populations over which statistics are given consist of changes in the variables listed in Table 4: hourly values are considered for $g_{c}, T_{s}$, NEE, and water and heat fluxes, daily values for LAI, and yearly values for peak biomass.

The fertilization effect of $\left(\mathrm{CO}_{2}\right)$ is responsible for an increase of the maximum LAI for all vegetation types between 1960 and 2000, also between 2000 and 2050 (Table 4, Fig. 1). The trend is particularly noticeable for wheat $\left(0.62 \mathrm{~m}^{2} \mathrm{~m}^{-2}\right.$ from 2000 to 2050) and is less marked for C4 plant like maize, as it could be expected, with only changes in LAI less than $0.1 \mathrm{~m}^{2} \mathrm{~m}^{-2}$. In the case of wheat, the high LAI increase simulated by ISBA-A-gs for 2050 is consistent with the Free Air $\mathrm{CO}_{2}$ Enrichment (FACE) study of Brooks et al. (2000) for fertilized wheat $(+11 \%)$.

For maize and conifer, in spite of a rise in LAI, the evapotranspiration is reduced. This is due to the reduction of $g_{c}$ and to the increase in water use efficiency in response to 
Table 4. Median difference of daily values of leaf area index (LAI), hourly values of canopy conductance (relative difference), leaf temperature, net ecosystem exchange of $\mathrm{CO}_{2}$ (NEE), water vapour flux, heat flux, and yearly values of peak aboveground biomass (relative difference) and optimum irrigation, between the 1960 and 2050 scenarios and the 2000 reference simulation, for 3 vegetation types: winter wheat, irrigated maize, and coniferous forest. The mean of the yearly (Y1-Y4) values are given, with the standard deviation. The values of leaf nitrogen concentration $\left(N_{L}\right)$, in \% of dry mass, derived from Eq. (2), are indicated.

\begin{tabular}{|c|c|c|c|c|c|c|}
\hline Variable & Wheat 1960 & Wheat 2050 & Maize 1960 & Maize 2050 & Conifer 1960 & Conifer 2050 \\
\hline LAI $\left(\mathrm{m}^{2} \mathrm{~m}^{-2}\right)$ & $-0.22 \pm 0.02$ & $+0.62 \pm 0.08$ & $-0.10 \pm 0.02$ & $+0.07 \pm 0.07$ & $-0.20 \pm 0.01$ & $+0.39 \pm 0.02$ \\
\hline Canopy conductance (relative difference in $\%$ ) & $-3.0 \pm 1.7$ & $+2.6 \pm 4.5$ & $+3.2 \pm 0.6$ & $-18.2 \pm 2.2$ & $+1.4 \pm 0.2$ & $-6.2 \pm 1.0$ \\
\hline Leaf temperature (degree $\mathrm{C}$ ) & $+0.04 \pm 0.02$ & $-0.05 \pm 0.05$ & $-0.06 \pm 0.01$ & $+0.42 \pm 0.05$ & $-0.01 \pm 0.01$ & $+0.07 \pm 0.02$ \\
\hline Net $\mathrm{CO}_{2}$ flux $\left(\mu \mathrm{mol} \mathrm{m}^{-2} \mathrm{~s}^{-1}\right)$ & $+2.5 \pm 0.5$ & $-7.9 \pm 1.7$ & $+4.5 \pm 0.3$ & $-9.2 \pm 1.1$ & $+3.8 \pm 0.3$ & $-11.8 \pm 0.5$ \\
\hline Water vapour flux $\left(\mathrm{W} \mathrm{m}^{-2}\right)$ & $-1.4 \pm 0.6$ & $+1.5 \pm 1.6$ & $+2.1 \pm 0.3$ & $-13.5 \pm 1.2$ & $+1.6 \pm 0.2$ & $-6.6 \pm 1.4$ \\
\hline Heat flux $\left(\mathrm{W} \mathrm{m}^{-2}\right)$ & $+0.9 \pm 0.4$ & $-1.0 \pm 1.0$ & $-1.2 \pm 0.3$ & $+8.6 \pm 1.0$ & $-1.3 \pm 0.2$ & $+5.6 \pm 1.3$ \\
\hline Yearly peak aboveground biomass (relative difference in \%) & $-12 \pm 2$ & $+32 \pm 4$ & $-7 \pm 0$ & $+15 \pm 2$ & - & - \\
\hline Yearly optimum irrigation $\left(\mathrm{mm} \mathrm{y}^{-1}\right)$ & - & - & $0 \pm 0$ & $-30 \pm 0$ & - & - \\
\hline $\mathrm{N}_{L}(\%)$ & 1.13 & 1.03 & 2.25 & 2.07 & 2.37 & 2.12 \\
\hline
\end{tabular}
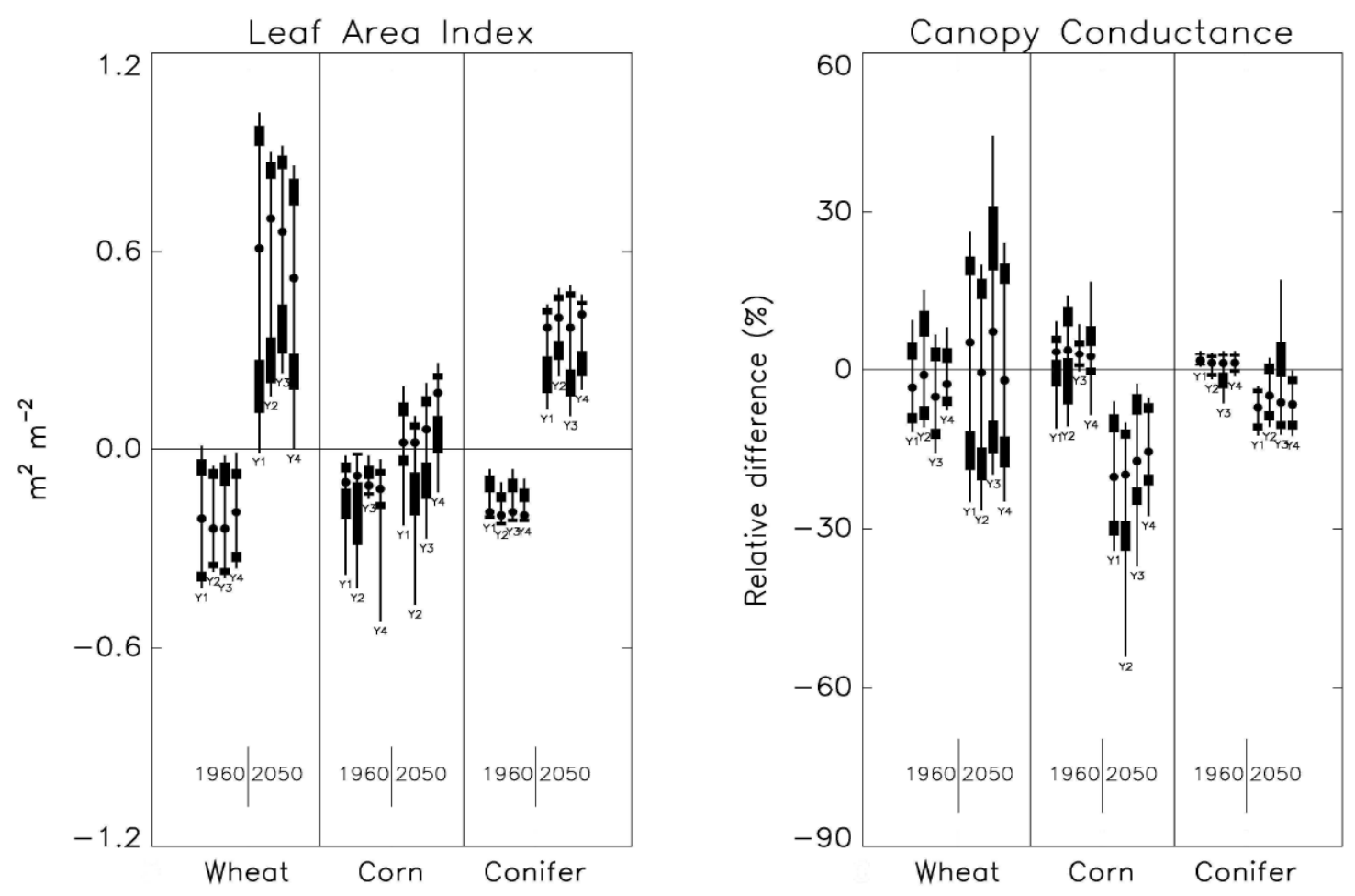

Fig. 2. Impact of 2 scenarios $\left(1960,2050\right.$, i.e. $\left(\mathrm{CO}_{2}\right)$ of 320 and $550 \mathrm{ppm}$, respectively) on (top) leaf area index, and (bottom) canopy conductance (relative difference). Median difference: closed circles; 5-95\% percentiles: fine line; 10-20\% percentile: closed box (bottom); 80-90\% percentile: closed box (top). Positive differences correspond to higher values in the scenario, compared with the 2000 reference simulation. The results are presented for four contrasting annual cycles (Y1 to Y4, Table 1) in southwestern France.

the $\left(\mathrm{CO}_{2}\right)$ rise. This effect is particularly significant for $\mathrm{C} 4$ plants (maize). In the case of maize, the optimum irrigation decreases in 2050 while the simulated maximum biomass increases. In the case of wheat, median changes in $g_{c}$ and evapotranspiration are small, and the two quantities tend to increase between 1960 and 2050. In this case, the fertilization effect and the $\mathrm{LAI}$ increase prevail $\left(\mathrm{CO}_{2}\right.$ is a strong limiting factor for $\mathrm{C} 3$ plants) and tend to mask the decrease in leaf stomatal conductance.

The median change in Ts is small, except for maize in 2050 ( +0.42 degree $C$, Table 4 , and more than +0.86 degree $\mathrm{C}$ for $10 \%$ of the distribution, not shown).

Since the median values in Table 4 may hide more complex features, the median difference is presented together 

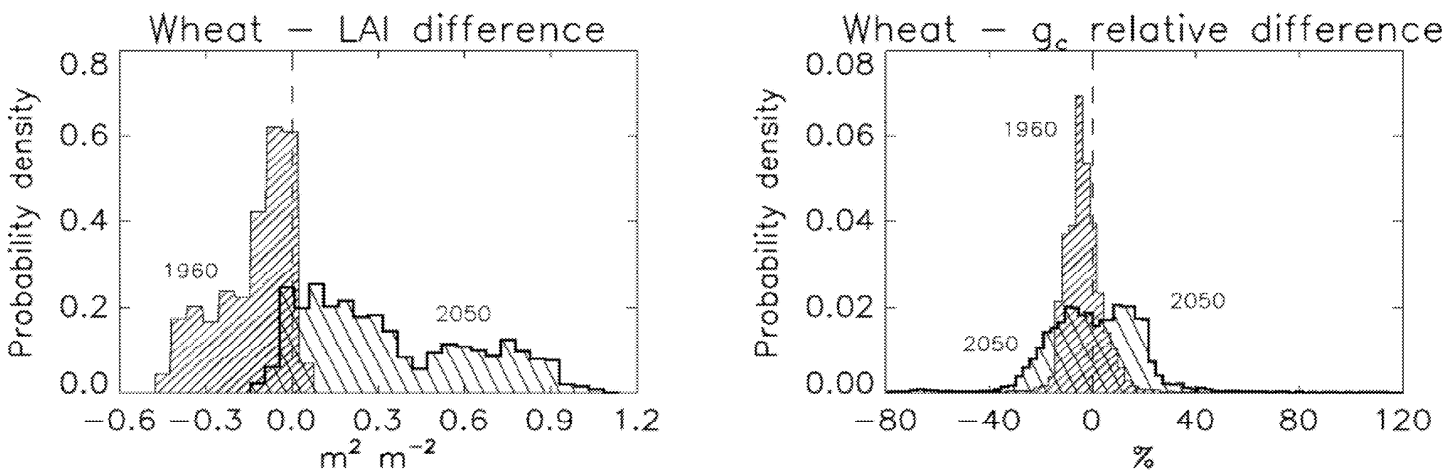

Fig. 3. Probability density functions of the simulated impact of changes in $\left(\mathrm{CO}_{2}\right)$ conditions on (left) leaf area index (LAI) and (right) canopy conductance $\left(g_{c}\right)$ of wheat, from 2000 to 1960 (fine line and dense hatching) and from 2000 to 2050 (thick line and sparce hatching).
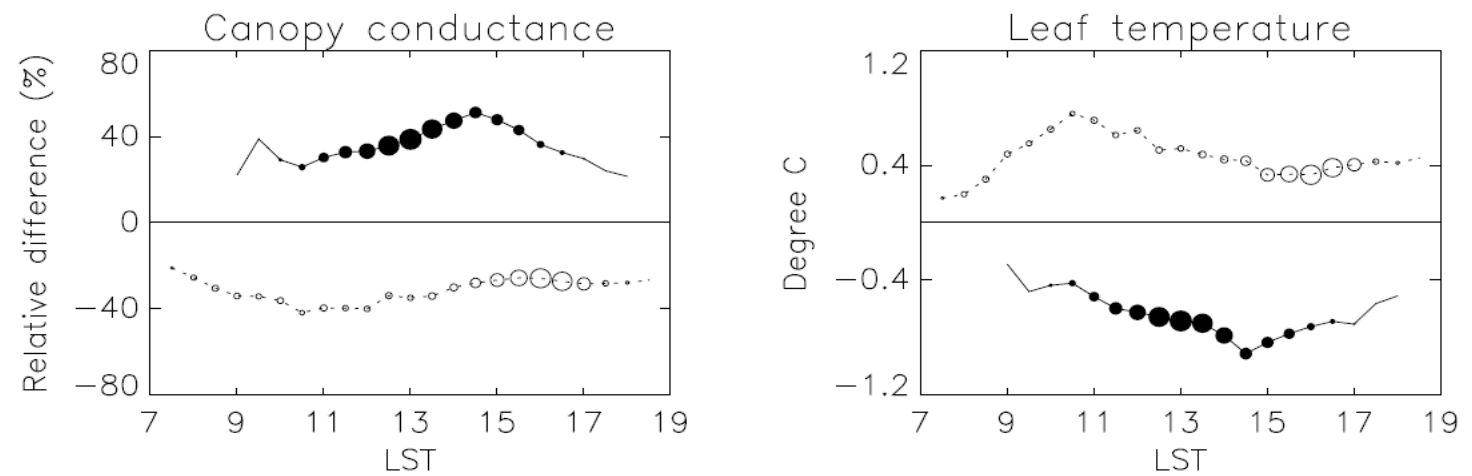

Fig. 4. Impact of the 2050 scenario $\left(\mathrm{CO}_{2}\right.$ of $\left.550 \mathrm{ppm}\right)$ on (left) the canopy conductance (relative difference) of winter wheat vs time (from 07:00 to 19:00 local standard time): average values above the $90 \%$ percentile and below the 10\% percentile (closed and open circles, solid and dotted lines, respectively). The probability of occurrence is represented by the radius of the circles. Right: the corresponding mean leaf temperature difference.

with 6 percentiles $(5,10,20,80,90$, and 95\%) in Fig. 2, for LAI and $g_{c}$, for each annual cycle. Most often than not, larger differences are simulated from 2000 to 2050 than from 1960 to 2000. In the case of wheat, large changes in $g_{c}$, either positive or negative, are simulated from 2000 to 2050 . The distribution of the difference in LAI and $g_{c}$ is bimodal: the differences in LAI and $g_{c}$ aggregate into two populations presenting either positive or negative values, as shown by Fig. 3 . The diurnal cycle of the 10 and $90 \%$ percentiles changes in $g_{c}$ are presented in Fig. 4, along with the corresponding changes in leaf temperature.

The meta-analysis of Yi02 revealed major uncertainties in leaf nitrogen response to $\left(\mathrm{CO}_{2}\right)$. The empirical description of the relative change in $N_{L}$ in response to a change in $\left(\mathrm{CO}_{2}\right)$ explains $41 \%$ of the variance in Yin02, only. Indeed, Eqs. (2) and (3) contain major uncertainties caused by experimental errors and by the difficulty in merging experimental data from diverse sources. The vast majority of $\left(\mathrm{CO}_{2}\right)$ enrichment experiments show that $N_{L}$ declines as $\left(\mathrm{CO}_{2}\right)$ increases. However, a number of experiments (e.g. 17\% of the experiments listed by Roderick et al., 1999) present no or insignificant response of $N_{L}$ to $\left(\mathrm{CO}_{2}\right)$.

In order to assess the effect of this uncertainty on the results presented in this study, a sensitivity analysis to $N_{L}$ was conducted. Two modelling experiments were performed: the influence of $\left(\mathrm{CO}_{2}\right)$ on $N_{L}$ was assumed (1) insignificant (i.e. no change on the value of $N_{L}$ ), and (2) twice the impact given by Eq. (2).

The impact of experiments (1) and (2) was found to be:

- small on the $g_{c}$ response to $\left(\mathrm{CO}_{2}\right)$, in all cases

- small for the wheat LAI response to $\left(\mathrm{CO}_{2}\right)$

- critical for the LAI response to $\left(\mathrm{CO}_{2}\right)$ of maize and conifer.

Experiment (1) increases the LAI response to $\left(\mathrm{CO}_{2}\right)$ of maize and conifer, to a level close to the LAI response simulated for wheat. Experiment (2) virtually suppresses the $\left(\mathrm{CO}_{2}\right)$ effect on LAI for the conifer and reverses the $\left(\mathrm{CO}_{2}\right)$ effect on LAI 
for maize (i.e. LAI declines as $\left(\mathrm{CO}_{2}\right)$ increases). This result is related to the values of the plasticity parameters $e$ and $f$ (Table 2) prescribed (from Gi06) for the three vegetation types. The parameter $e$ represents the SLA sensitivity to $N_{L}$. The maize $e$ value is almost twice as large as that for wheat, and the conifer presents an intermediate value. Note that the values of $e$ and $f$ given by Gi06 are derived from a metaanalysis, which is affected by uncertainties, also.

In conclusion, this sensitivity analysis suggests that the $g_{c}$ response to $\left(\mathrm{CO}_{2}\right)$ is relatively insensitive to uncertainties in the representation of nitrogen dilution. On the other hand, the prescribed value of SLA sensitivity to $N_{L}$ has a large impact on the LAI response to $\left(\mathrm{CO}_{2}\right)$.

\subsection{A bimodal response of $g_{c}$ : the wheat case}

A bimodal response of LAI and $g_{c}$ to $\left(\mathrm{CO}_{2}\right)$ is simulated for wheat in 2050. In particular, $g_{c}$ either increases or decreases in our simulations, with about the same probability. The analysis of the wheat simulations shows that the simulated net effect of $\mathrm{CO}_{2}$ on canopy conductance may be either positive or negative (Fig. 4) and this is a seasonal variation (Fig. 5).

Figure 4 presents dawn-to-dusk curves of the most significant (10\% highest and $10 \%$ lowest) hourly values of relative difference in $g_{c}$ and absolute difference in $T_{s}$. The probability distribution of the differences is not uniform in time. In Fig. 4, the probability of observing a difference at a given time of the day is represented by the size of the circles. It is shown that (1) the highest increase of $g_{c}$ and the concomitant decrease of $T_{S}$ are more frequently observed around noon (from 12:00 to 14:00 LST) ; (2) the highest decrease of $g_{c}$ and the concomitant increase of $T_{S}$ are observed, mainly, in the afternoon (from 15:00 to 17:00 LST).

The highest simulated differences are not shown in Figs. 2 and 4 . They can be very large because the hourly values considered here are subjected to a high variability (caused by changes in LAI, soil moisture, and meteorological conditions). In our simulations, $g_{c}$ may increase up to $+540 \%$ (and $T_{s}$ presents a concomitant decrease of -4.4 degree C) and decrease down to $-80 \%$ (and $T_{s}$ presents a concomitant decrease of +1.9 degree $C$ ).

Figure 5 shows that the $g_{c}$ increase is often observed at the start of the growing season (March) and during the regrowth (September). Indeed, the relative LAI increase of wheat presents a maximum value ( $25 \%$ or more) in March, and a second maximum is simulated in September for the dry annual cycles Y3 and Y4. When the LAI enhancement prevails over the antitranspirant effect of $\mathrm{CO}_{2}$, the increase in $g_{c}$ and the decrease in Ts are particularly significant from 12:00 to $14: 00 \mathrm{LST}$. This latter is the consequence of a radiative effect, accounted for in ISBA-A-gs. The influence of LAI on $g_{c}$ is enhanced along daytime, in particularly thanks to a better penetration the solar radiation within the vegetation canopy around noon. The variable $g_{c}$ is all the more increased since the decrease of $T_{S}$ tends to reduce the leaf-to-air saturation deficit (in general, the saturation deficit presents maximum values between 12:00 and 14:00 LST).

The antitranspirant effect of $\mathrm{CO}_{2}$ prevails over the LAI enhancement in springtime (April to June), during the most active period of carbon uptake by the wheat crop. At that time, LAI peak is reached with values ranging from 3 to $4 \mathrm{~m}^{2} \mathrm{~m}^{-2}$ in April-May, and from 4 to $5 \mathrm{~m}^{2} \mathrm{~m}^{-2}$ in June (except for 2003 with less than $1 \mathrm{~m}^{2} \mathrm{~m}^{-2}$ in June). It yields a decrease in $g_{c}$ particularly significant from 15:00 to 17:00 LST. Indeed, LAI increase does not necessarily trigger a rise in $g_{c}$, due again to a radiative effect: increasing high LAI values have an adverse effect on the penetration of light into the canopy, which tends to increase the proportion of shaded leaves, especially as the sun moves away from the zenith direction.

In the case of conifer, the antitranspirant effect is more significant than for wheat. However, in this modeling study, the $\mathrm{CO}_{2}$ effect is considered, only. In the case of forests, other factors may influence the forest's growth and LAI, such as long term nitrogen deposition or changes in forest management. These additional factors may amplify the $\mathrm{CO}_{2}$ effects on LAI (Cannell, 1999).

\subsection{Biomass}

As far as biomass is concerned, 2050 results can be compared with those of Long et al. (2006), based on enclosure and FACE studies at $550 \mathrm{ppm}$. They show that enclosure studies give an average yield increase of 31 and $18 \%$ for wheat and $\mathrm{C} 4$ crops, respectively. They also show that the FACE studies give much lower values: 13 and $0 \%$. Our 2050 wheat and maize results (Table 4) are consistent with the enclosure estimates (we obtain 32 and $15 \%$, respectively), not with the FACE ones. Note that the FACE results are based on a very small number of experiments (4 annual cycles for wheat at the same site, only one annual cycle for maize).

\subsection{Irrigation}

The maize simulations show that, for a given annual cycle, the 2050 scenario tends to reduce the required amount of irrigation (Table 4), while increasing the biomass production. However, in the future, Y3 and Y4 years may be more common than now and the irrigation demand (Table 3) will increase: there is a factor 2 or more from the optimal irrigation of Y1 to Y3 and Y4.

\section{Conclusions}

An operational land surface model was used in order to perform a sensitivity study to $\left(\mathrm{CO}_{2}\right)$. This modelling study was conducted for climatic conditions found in southwestern France. Our simulations show that: 

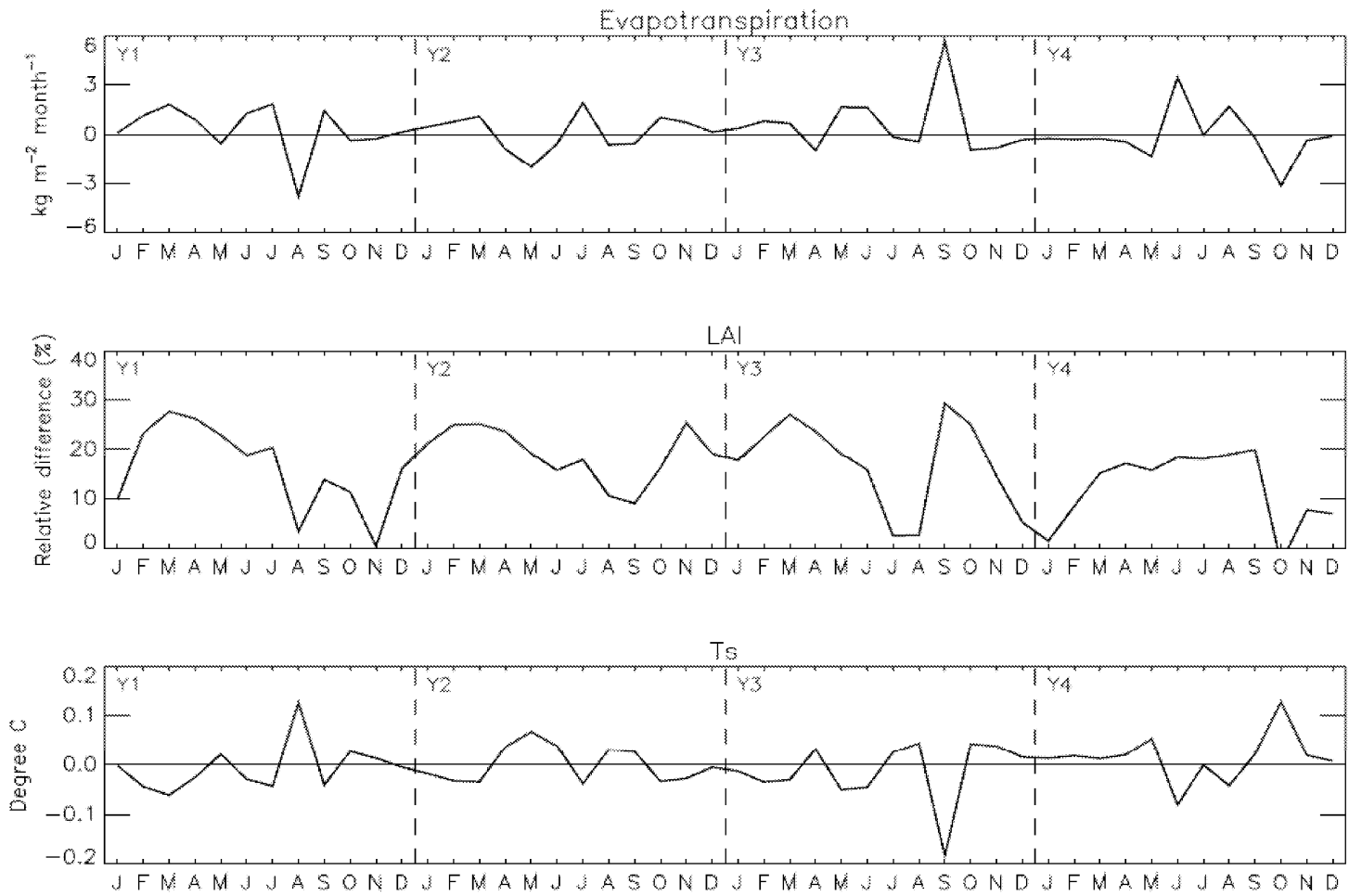

Fig. 5. Impact of the 2050 scenario $\left(\left(\mathrm{CO}_{2}\right)\right.$ of $\left.550 \mathrm{ppm}\right)$ on winter wheat, for four contrasting years (Y1 to Y4, Table 1). From top to bottom: difference in monthly evapotranspiration, relative difference in LAI, monthly average difference in leaf temperature.

- In general, changes in LAI and canopy conductance are more significant from 2000 to 2050 than from 1960 to 2000, showing that although the need for using of a $\mathrm{CO}_{2}$-responsive land surface model in operational NWP simulations was not expressed so far, the $\mathrm{CO}_{2}$ effect on vegetation may have to be accounted for in the future in order to avoid seasonal and diurnal biases in the simulations.

- The impact of increasing biomass and LAI due to increased $\left(\mathrm{CO}_{2}\right)$ must be accounted for since it tends to compensate for the antitranspirant effect. This effect seems to be particularly significant for wheat. Many studies suggest that changes in LAI caused by $\left(\mathrm{CO}_{2}\right)$ are important (e.g. Piao et al., 2006 over the northern hemisphere) and it is likely that adding the $\mathrm{CO}_{2}$ fertilisation mechanism would change the conclusions that Gedney et al. (2006) derived from their simulations.

- The net effect of $\mathrm{CO}_{2}$ on canopy conductance, leaf temperature, and latent and sensible heat fluxes may be either positive or negative (especially for C3 plants) and may affect the seasonal variability.

- For wheat, the simulated net $\mathrm{CO}_{2}$ effect on canopy conductance may depend, to a large extent, on the way light interception within the canopy is simulated. At the canopy level, light can be limiting and the radiative transfer within the canopy has to be represented. The light interception mechanism is complex. It depends to a large extent on LAI but not only. For example, leaf orientation influences the distribution of solar radiation within the canopy. For wheat, Brooks et al. (2000) show that leaf orientation may depend on the nutrient availability and may change with increasing $\left(\mathrm{CO}_{2}\right)$. This effect is not accounted for in the model used in this study.

- An extensive $\mathrm{CO}_{2}$-driven reduction of canopy conductance is simulated for the irrigated maize and the coniferous forest. The reduction is particularly large for maize, from 2000 to $2050(-18 \%)$, and triggers a drop in optimum irrigation $\left(-30 \mathrm{~mm} \mathrm{y}^{-1}\right)$.

Acknowledgements. The authors thank the anonymous reviewers, as well as Drs P. Ciais (LSCE), A. Olioso (INRA) and L. Kergoat (CESBIO) for fruitful discussion.

Edited by: S. Quegan 


\section{References}

Agreste, http://www.agreste.agriculture.gouv.fr, last access: September 2007, 2007.

Bondeau, A., Smith, P. C., Zaehle, S., Schaphoff, S., Lucht, W., et al.: Modelling the role of agriculture for the 20th century global terrestrial carbon balance, Global Change Biol., 13(3), 679-706, 2007.

Berbigier, P., Bonnefond, J. M., and Mellmann, P.: $\mathrm{CO}_{2}$ and water vapour fluxes for 2 years above Euroflux forest site, Agric. For. Meteorol., 108, 183-197, 2001.

Brooks, T. J., Wall, G. W., Pinter Jr., P. J., Kimball, B. A., LaMorte, R. L., et al.: Acclimation response of spring wheat in a free-air $\mathrm{CO}_{2}$ enrichment (FACE) atmosphere with variable soil nitrogen regimes, 3. Canopy architecture and gas exchange, Photosynth. Res., 66, 97-108, 2000.

Calvet, J.-C., Noilhan, J., Roujean, J.-L., Bessemoulin, P., Cabelguenne, M., Olioso, A., and Wigneron, J.-P.: An interactive vegetation SVAT model tested against data from six contrasting sites, Agric. For. Meteorol., 92, 73-95, 1998.

Calvet, J.-C. and Soussana, J.-F.: Modelling $\mathrm{CO}_{2}$-enrichment effects using an interactive vegetation SVAT scheme, Agric. For. Meteorol., 108(2), 129-152, 2001.

Calvet, J.-C., Rivalland, V., Picon-Cochard, C., and Guehl, J.-M.: Modelling forest transpiration and $\mathrm{CO}_{2}$ fluxes - response to soil moisture stress, Agric. For. Meteorol., 124(3-4), 143-156, doi:10.1016/j.agrformet.2004.01.007, 2004.

Cannell, M. G. R.: Relative importance of increasing atmospheric $\mathrm{CO}_{2}, \mathrm{~N}$ deposition and temperature in promoting European forest growth, in: Causes and consequences of accelerating tree growth in Europe, EFI Proceedings, vol. 27, edited by: Karjalainen, T., Spiecker, H., and Laroussinie, O., 25-41, European Forest Institute, Helsinki, 1999.

Debaeke, P., Bertrand, M., and Gary, C.: Sensibilité à la sécheresse des systèmes de culture, in Sécheresse et agriculture, edited by: Amigues, J. P., Debaeke, P., Itier, B., Lemaire, G., Seguin, B., Tardieu, F., Thomas, A., INRA, 2006.

De Rosnay, P., Calvet, J.-C., Kerr, Y., Wigneron, J. P., Lemaître, F., et al.: SMOSREX: A long term field campaign experiment for soil moisture and land surface processes remote sensing, Remote Sens. Env., 102(3-4), 377-389, 2006.

Dolman, A. J., Moors, E. J., and Elbers, J. A.: The carbon uptake of a mid latitude pine forest growing on sandy soil, Agric. For. Meteorol., 111, 157-170, 2002.

Dolman, H., Noilhan, J., Durand, P., Sarrat, C., Brut, A., et al.: CERES, the Carboeurope Regional Experiment Strategy in Les Landes, SW France, Bull. Am. Meteorol. Soc., 87(10), 13671379, doi:10.1175/BAMS-87-10-1367, 2006.

Douville, H., Planton, S., Royer, J.-F., Stephenson, D. B., Tyteca, S., Kergoat, L., Lafont, S., and Betts, R. A.: Importance of vegetation feedbacks in doubled- $\mathrm{CO}_{2}$ climate experiments, J. Geophys. Res., 105(D11), 14 841-14 861, 2000.
Field, C., Jackson, R., and Mooney, H.: Stomatal responses to increased $\mathrm{CO}_{2}$ : implications from the plant to the global-scale, Plant Cell Environ., 18, 1214-1255, 1995.

Fung, I. Y., Doney, S. C., Lindsay, K., and John, J.: Evolution of carbon sinks in a changing climate, Proc. Natl. Acad. Sci., 102, 11 201-11 206, 2005.

Gedney, N., Cox, P. M., Betts, R. A., Boucher, O., Huntingford, C., and Stott, P. A.: Detection of a direct carbon dioxide effect in continental river runoff records, Nature, 439, 835-838, doi:10.1038/nature04504, 2006.

Gibelin, A.-L., Calvet, J.-C., Roujean, J.-L., Jarlan, L., and Los, S.: Ability of the land surface model ISBA-A-gs to simulate leaf area index at the global scale: comparison with satellites products, J. Geophys. Res., 111, D18102, doi:10.1029/2005JD006691, 2006.

Keeling, C. D., Chin, J. F. S., and Whorf, T. P.: Increased activity of northern vegetation inferred from atmospheric $\mathrm{CO}_{2}$ measurements, Nature, 382, 146-149, doi:10.1038/382146a0, 1996.

Long, S. P., Ainsworth, E. A., Leakey, A. D. B., Nösberger, J., and Ort, D. R.: Food for thought: Lower-than-expected crop yield stimulation with rising $\mathrm{CO}_{2}$ concentrations, Science, 312, 1918 1921, 2006.

Martin, E., Le Moigne, P., Masson, V., et al.: Le code de surface externalisé SURFEX de Météo- France, Ateliers de Modélisation de l'Atmosphère (http://www.cnrm.meteo.fr/ ama2007/), Toulouse, 16-18 January, 2007.

Muñoz Sabater, J., Jarlan, L., Calvet, J.-C., Bouyssel, F., and De Rosnay, P.: From near-surface to root-zone soil moisture using different assimilation techniques, J. Hydrometeorol., 8(2), 194206, 2007.

Piao, S., Friedlingstein, P., Ciais, P., Zhou, L., and Chen, A.: Effect of climate and $\mathrm{CO}_{2}$ changes on the greening of the northern hemisphere over the past two decades, Geophys. Res. Lett., 33 L23402, doi:10.1029/2006GL028205, 2006.

Rivalland, V., Calvet, J.-C., Berbigier, P., Brunet, Y., and Granier, A.: Transpiration and $\mathrm{CO}_{2}$ fluxes of a pine forest: modelling the undergrowth effect, Ann. Geophys., 23, 291-304, 2005, http://www.ann-geophys.net/23/291/2005/.

Roderick, M. L., Berry, S. L., and Noble, I. R.: The relationship between leaf composition and morphology at elevated $\mathrm{CO}_{2}$ concentrations, New Phytol., 143, 63-72, 1999.

Teyssier, F.: Consommations d'eau pour irrigation sur 2001-2005 en Midi-Pyrénées, Agreste Midi-Pyrénées, Données, 35, http:// agreste.agriculture.gouv.fr/IMG/pdf/R7306A09.pdf, 2006.

Viovy, N.: PILPS carbon first experiment, http://www.lsce.cnrs-gif. $\mathrm{fr} / \mathrm{cb} /$ carbone/pilpsc1/, 2003.

Yin, X.: Responses of leaf nitrogen concentration and specific leaf area to atmospheric $\mathrm{CO}_{2}$ enrichment: a retrospective synthesis across 62 species, Global Change Biol., 8(7), 631-642, 2002. 